\title{
The Men and the Boys, Twenty Years On
}

\section{Revisiting Raewyn Connell's Pivotal Text}

\author{
Victoria Cann, Sebastián Madrid, Kopano Ratele, Anna Tarrant, \\ and Michael R.M. Ward with Raewyn Connell
}

It is twenty years since the publication of Raewyn Connell's highly influential text The Men and the Boys. This book, building on feminist and pro-feminist perspectives of gender formation, was written over a ten-year period from the late 1980s to the late 1990s. It was published five years after the release of the groundbreaking text Masculinities (1995) and tackled multiple issues concerning boys and men. While providing an important platform and summary of where the research from the social science and humanities on men and masculinities stood in the year 2000, the book also contained a theoretical framework for understanding men and masculinities as part of gender relations. Importantly, the future direction of the field was outlined, and suggestions were made as to likely future agendas. These subjects included investigating the implications of globalization and its different characteristics on gender formation, the role of men's bodies, the impact of the media and culture in men's lives, sexuality, education, health, politics, change, violence, and peace. In recent years, questions about the lives and experiences of men and boys continue to raise remarkable media interest, public concern, and controversy on a global scale. Global changes in practices of knowledge have ensured that across the humanities and social sciences, research in the field of masculinities (of all ages) has continued to flourish and expand.

It is evident that scholarly work outside Anglophone countries has traditionally been given less space and remains less widely acknowledged in the field, although there is evidence of change in this regard (see Gottzén et al. 2020). These movements toward greater international perspectives have taken place not only in diverse research settings, but through developing more sophisticated theoretical positions and interdisciplinary (and increasingly post-disciplinary) perspectives. New and important questions 
continue to arise around "who is?" and "who is not?" as well as "what is?" and "what is not?" included in the field (see Bridges 2019).

As scholars deeply influenced by Connell's work ourselves, we saw the twentieth anniversary of this publication as a timely opportunity to revisit and celebrate, especially given the book's substantive focus on boys and young men. As the journal Boyhood Studies makes clear, boyhood is a complex, diverse, and processual concept; it is multiply defined and subject to change over time and culture. As Connell notes in her own contribution to this special issue:

To speak of boyhood, then, is not to speak of a universal. This is a terrain with changing boundaries and characteristics, a field of struggle over legitimate definitions, practices and resources. The Men and the Boys mapped boyhood largely through relationships: between childhood and adulthood along pathways of masculinity formation; between adults and children in constraints and pedagogies; between boys and girls, and among groups of boys, in the everyday life of schools, homes and peer groups. (Connell 2020: 17)

When we launched the call for papers for this special issue in early 2020 , none of the editorial team could foresee the global pandemic that would unfold. However, we have remained determined to mark the twentieth anniversary year of the book and we thank the authors, editorial board members, peer reviewers, and staff at Berghahn, for their commitment and for working to tight deadlines to achieve this. We were also delighted with the high volume of submissions we received. Indeed, selecting abstracts was a very difficult yet inspiring process. Given the excellence of the submissions and their diverse focus, we took the decision to create two special issues (13.2 and 14.1) to celebrate this important work.

We envisaged the collection would contain different types of contributions from across the globe and from people of all career stages. Connell herself made some initial suggestions as to who to invite, which led to submissions from those who had worked with her or whose careers have developed alongside hers. We also received abstracts from a new generation of scholars whose work has been influenced by her. The three types of contributions we sought were as follows: empirical articles that applied Connell's theorizing in some way to their own research; commentary pieces that used The Men and the Boys to discuss contemporary issues relevant to boys and young men; and shorter reflective pieces by scholars outlining how important The Men and the Boys and Connell's work more broadly have been to their own. The empirical articles, commentary, and reflective pieces accepted for the pair of special issues demonstrate the enduring 
global applicability of the concepts developed in Connell's book, enhancing our contemporary understanding of boys and young men's practices as they negotiate pathways to adulthood.

\section{Content of the Issue}

We feel very privileged to start the first of these two special issues with an article from Raewyn Connell herself, providing her own account of the intellectual and political context in which The Men and the Boys was written. In her account, Connell tracks her own research trajectory leading to the book. She elaborates how it evolved slowly over a ten-year period, with the various chapters being written from the late 1980s to the late 1990s. Her observations demonstrate the value when ideas are developed over time, something today's academia, with its pressures to produce extensive material and to conduct quicker research, rarely allows for. These chapters reflect how debates were shifting at that time. What is clear, however, is Connell's clear concern with explaining and theorizing practical issues of change in masculinities and gender relations. In her article, Connell also offers a summary of new directions taken in the field that have been influenced by the book over the past twenty years and the way the book dealt with boyhood as a field of study.

The second article is the first of four to showcase empirical studies that develop Connell's theorizing from The Men and the Boys. Connell's discussions are developed by James Messerschmidt, another influential figure in the field of men and masculinities. In 2005 (alongside Connell), Messerschmidt expanded and reformulated the key concept of "hegemonic masculinities" (Connell and Messerschmidt 2005), which conceptually, has shaped the field ever since. In this article, the author builds concepts of hegemonic masculinities, emphasized femininity, and related others articulated by Raewyn Connell (2000) in The Men and the Boys, as well as Gender and Power (Connell 1987), summarizing and analyzing a case study of an 18-year-old American young man who was identified at school as a "wimp" and who eventually engaged in sexual violence. Messerschmidt argues that subordinated boys rarely are-if at all-discussed in detail in the literatures on violence. The article reveals the interrelationship among in-school bullying, reflexivity, embodiment, and the social construction of dominant and hegemonic masculinities through the commission of adolescent sexual violence. The analysis forwarded by Messerschmidt demonstrates the con- 
tinued relevance of Connell's work for boys and young men by building on and expanding upon Connell's ideas.

In the third article, Utsa Mukherjee draws upon Connell's concepts in a qualitative study with 11-to-12-year-old middle-class British Indian boys and their parents to unpack the ways notions of young masculinities are negotiated within the context of children's leisure. Taking a relational approach, Mukherjee argues that the leisure-based masculinities of children are simultaneously generationed and gendered. By interrogating the intersection of what Connell in The Men and the Boys terms "gender-configurations of practice" (Connell 2000: 28) and what childhood sociologists call the "generational order," Mukherjee demonstrates how leisure-based young masculinities are forged within children's inter- (parent-child) and intra(child-child) generational relationships in the context of leisure. Mukherjee concludes with a call for greater engagement with intersectional frameworks to address questions of power and social relationships in the study of boys' masculinity that simultaneously recognizes both the gendered and generational structures of children's everyday lives.

The main goal of the fourth article by Katarzyna Wojnicka, again drawing on Connell's theorizing, is to show how age shapes attitudes to non-heterosexuality among migrant men and boys living in Germany and Sweden. A particular focus is the differing perceptions and narratives identified during several qualitative research projects with adult and young migrant men in Germany and Sweden regarding sexual diversity. The first set of data comes from a sub-study on Polish adult male migrants in Munich and Berlin, Germany, conducted between 2014 and 2018, the other from a research project with young migrants and refugees living in Berlin, conducted in 2019. Finally, the last set of data comes from an ongoing project where Polish single men living in Gothenburg, Sweden, are one of the researched communities. Like the previous article by Mukherjee, Wojnicka underlines the significance of analyzing men's masculinities through intersectional lenses, with a special focus on age, which, along with other factors such as social class, ethnicity, and citizenship, to name a few, situates people in certain positions in gender hierarchies and deeply influences their masculine practices and narratives.

The work of Cinthia Torres Toledo and Marília Pinto de Carvalho is explored in the fifth article. They, in dialogue with Connell's observations of the schooling of boys and hierarchies of masculinities, analyze how the collective conceptions of peer groups influence the school engagement of Brazilian boys. Drawing on ethnographic research with students around 
the age of 14 at an urban state school in the periphery of Sáo Paulo, Brazil, Toledo and Carvalho argue that the hierarchization process between two groups of boys demonstrates the existence of a collective notion of masculinity that works against school engagement. While this might be well evidenced in the Anglophone academic literature, the authors argue that this association is rather uncommon in the Brazilian literature. The article therefore makes an important contribution by describing and analyzing the challenges faced by Black working-class Brazilian boys to establish more positive educational trajectories.

The first of three commentary pieces uses The Men and the Boys (and Connell's work more broadly) as a departure point for thinking about key contemporary issues for boys and young men. Steve Roberts and Karla Elliott argue that "men in the margins" are often simplistically depicted as regressive and violent in response to their marginalization. Focusing on representations of working-class boys and men in this article, Roberts and Elliott illustrate the stereotypical treatment of "men in the margins" more broadly, making clear that this goes against Connell's treatment of such men in The Men and the Boys. Conversely, they argue that privileged boys and men are more commonly held up by Critical Studies of Men and Masculinities scholars as paragons of progressive change. In this article, the authors argue that the characterization of boys and men in the margins as regressive and patriarchal impedes the ability to address problems like violence, misogyny and homophobia and overlooks the possibilities for transformation that emerge among marginalized communities.

In the seventh article, another commentary piece, Amrita De draws critical insights from Raewyn Connell's The Men and the Boys to unpack the gendered nature of neoliberal right-wing populist governance in India and the United States, reflecting on the effects of this type of leadership on young masculinities. De argues that Connell's prescient work, which in its conception was targeted toward forging new inroads in theoretical research in masculinity studies, continues to provide a vital heuristic model to make better sense of the present condition.

The third commentary piece by Robert Morrell, a leading masculinities scholar in South Africa, reflects on the importance of Connell's work to the country since the era of apartheid. Morrell argues that the study of masculinity in South Africa scarcely existed before the1990s. A minor interest in gender was focused on women and inequality. It was into this environment that Connell's ideas were introduced, adopted, and adapted. Morrell discusses how Connell herself made numerous trips to South Africa 
in the 1990s and 2000s and found a ready reception for her theories about masculinity. Morrell argues that South Africa was in transition, feeling its way from white minority rule and authoritarianism toward democracy and a commitment to ending poverty, inequality, racism, and the oppression of women. This article provides valuable insights about how Raewyn's ideas traveled, energized scholarship, created a new research interest in men and masculinity, and stimulated gender activism.

Finally, building on Sara Delamont's (2020) personal account of Connell, in the final two articles of this special issue, leading scholars in the field of men and masculinities offer short reflections on the role of Connell's work in their own lives and its influence on their research interests. In the first of these contributions, Marcus B. Weaver-Hightower eloquently describes the research methodology used by Cornell and how, during life history interviews, her skills as an interviewer emerged. In appreciation of the role of Connell's work, our final article by the new editors of the leading journal in the field of men and masculinities Joseph D. Nelson, Tristan Bridges, and Kristen Barber reflect on Connell's influence on their new vision and draw on her intersectional and feminist stance to take the journal forward.

We hope readers enjoy the first of our two special issues, just as much as we enjoyed putting it together. The quality, international scope, and diversity of topics showcased in this first special issue alone, are testament to the huge value and applicability of Connell's contributions to the Boyhood Studies field. We look forward to publishing the linked second issue, which will outline further the continued relevance and application of Connell's work in diverse global settings.

Victoria Cann is an Associate Professor in the Interdisciplinary Institute for the Humanities at the University of East Anglia where she directs the MA in Gender Studies. Her research interests include youth gender identities, identity formation, intersectional feminist politics, and feminist research methods. She is author of the book Girls Like This, Boys Like That: The Reproduction of Gender in Contemporary Youth Cultures (I.B. Tauris) and sits on the editorial board of Boyhood Studies, Journal of Gender Studies and is on the Executive Committee of the Gender and Education Association. Email: v.cann@uea.ac.uk

Sebastián Madrid is a Senior Researcher at the United Nations Development Program in Chile, an Adjunct Assistant Professor at the Institute of Sociology at the Catholic University of Chile, and a Research associ- 
ate in the PIA-ANID Project SOC180023, The Formation of the Gender Norm. His research interests include men and masculinities, elites and social stratification, biographical research, and the sociologies of education and politics. His most recent book is Masculinities in Latin América: Twenty Years of Research and Policy for Gender Equality (2020, co-edited with Teresa Valdés and Roberto Celedón). Email: smadridp@gmail.com

Kopano Ratele is the Director of the South African Medical Research Council Masculinity \& Health Research Unit and Professor at the University of South Africa where he runs the Transdisciplinary African Psychologies Programme. He has published extensively and his books include There Was This Goat: Investigating the Truth Commission Testimony of Notrose Nobomvu Konile (2009, co-authored with Antjie Krog and Nosisi Mpolweni), Liberating Masculinities (2016), Engaging Youth in Activism, Research and Pedagogical Praxis: Transnational and Intersectional Perspectives on Gender, Sex, and Race (2018, co-edited with Jeff Hearn, Tammy Shefer, and Floretta Boonzaier), and The World Looks Like This from Here: Thoughts on African Psychology (2019). Email: Kopano.Ratele@mrc.ac.za

Anna Tarrant is an Associate Professor at the University of Lincoln and is a UKRI Future Leaders Fellow. Her research interests include men and masculinities, family life, the lifecourse, and methodological developments in qualitative secondary analysis. Her current funded study, "Following Young Fathers Further," is a qualitative longitudinal, participatory study of the lives and support needs of young fathers. She is a co-editor of Sociological Research Online and an editorial board member of Sociology, Gender, Place and Culture and Boyhood Studies. Email: atarrant@lincoln.ac.uk

Michael R. M. Ward is Senior Lecturer in Social Sciences at Swansea University. His work centers on the performance of working-class masculinities within and beyond educational institutions. He is the author of the award-winning book From Labouring to Learning: Working-Class Masculinities, Education and De-industrialization (2015) and editor of Boyhood Studies: An Interdisciplinary Journal. Email: m.r.m.ward@swansea.ac.uk 


\section{References}

Bridges, Tristan. 2019. "The Costs of Exclusionary Practices in Masculinities Studies." Men and Masculinities 22 (1):16-33.

Connell, Raewyn 1987. Gender and Power: Society, the Person and Sexual Politics. Cambridge: Polity Press.

Connell, Raewyn 1995. Masculinities. Cambridge: Polity Press.

Connell, Raewyn 2000. The Men and the Boys. Cambridge: Polity Press.

Connell, Raewyn 2020. "Making The Men and the Boys." Boyhood Studies 13 (2): 9-19.

Connell, Raewyn, and James W. Messerschmidt. 2005. "Hegemonic Masculinity: Rethinking the Concept." Gender \& Society 19 (6): 829-859.

Delamont, Sara. 2020. "Reading Raewyn, Reflections on a Lifelong Inspiration." Boyhood Studies 13 (1): 131-134.

Gottzén, Lucas, Ulf Mellström, and Tamara Shefer. 2020. Routledge International Handbook of Masculinity Studies. Oxford: Routledge. 